\title{
Guiding Visually Impaired People by Transmitting Navigational Instructions to Wearable Vibrating Belt Systems
}

\author{
Reyes Adame M., Möller K., Seemann E. \\ Institute of Technical Medicine, Furtwangen University, Germany \\ rey@hs-furtwangen.de
}

\begin{abstract}
In the present paper we describe four vibrating systems which give blindfolded people navigational instructions by stimulating their skin receptors. The prototypes were developed in different ways and with different encodings for navigating commands. To compare the performance of the systems they were tested in a trail with obstacles by a blindfolded person and a second person transmitting the navigating commands to the systems. The vibrating belt systems were proven to be easy to use and simple kept encodings seemed to be superior to more complex systems.
\end{abstract}

Keywords: Navigational instructions, vibrotactile signal encodings, collision avoidance, visually impaired.

\section{Introduction}

Referred to the latest numbers from the World Health Organization (WHO), 246 million people have a vision disorder and 39 million are blind [1]. These people have a low capacity to perceive their environment. To improve their environmental perception, they have nowadays some established aids like the white cane or guide dog. These aids have some disadvantages, e.g. with the cane people may recognize obstacles on the ground but obstacles at a height of the head or chest will not be detected [2]. In order to solve this problem a lot of approaches e.g. with ultrasound improved sticks have been proposed. These sticks typically use the auditory system for the transmission of information, but for spatial orientation the auditory system is already used by visually impaired people and can be disturbed by additional acoustic signals. Therefore these approaches have not found wide acceptance [2].

To avoid these disadvantages another approach which uses vibrotactile stimuli of skin receptors using ordinary mobile phone vibration motors for information transfer is introduced. The stimuli of skin receptors are ideal for navigation due to the great surface area of the skin and the fact that the majority of these receptors are not active during navigation [3]. The focus in this work is set on different encodings of four vibrating systems for navigational instructions.

\section{Methods}

\section{A. Basic Hardware Set Up}

The four vibrating belt prototypes were developed by four groups (three groups of two members and one group of three) of engineering students. During the development process of the prototypes the students were supervised by a professional employee. All prototypes consisted of the following basic components:

- Vibration motors (model number LA4-432A, available by the Nidec Copal Company USA) for the stimulation of the skin receptors. The size of these motors is $16 \times 5 \times 6 \mathrm{~mm}$ and the rated voltage, speed and current is $3 \mathrm{~V}, 9500 \mathrm{rpm}$ and $66 \mathrm{~A}$.

- Arduino BT board for a wireless control of the vibration motors. This board has an ATmega328 microcontroller and a Bluegiga WT11 Bluetooth module.

- Power supply for the Arduino BT board and the vibration motors. This was realized using four 1.2 V AA batteries in a battery pack for the Arduino BT board and three $1.2 \mathrm{~V}$ AA batteries for the vibration motors.

- Motor driver (Dual Full-Bridge Driver L298 from the STMicroelectronics Company, Switzerland) to switch to the needed rated voltage of the vibration motors.

\section{B. $\quad$ Trail with obstacles}

To evaluate the performance of the vibrating systems, the prototypes were tested in a trail with obstacles. One member of each group wearing the vibrating system was blindfolded and guided via wireless commands from a Notebook or Tablet-PC to the vibrating systems by a second group member. The total distance of the track in the first run was about $25 \mathrm{~m}$ and included diverse left / right curves with different curvature and one small bump. For the second run the track was enlarged by additional $10 \mathrm{~m}$ including a barrier which had to be crossed.

\section{Positioning, signal coding and number of vibration motors}

Except of the basic hardware set up the prototypes were developed in different ways. Figure 1 shows the four vibrating systems. Prototype 1 consists of a belt with eight vibration motors and a carry case for storage of the hardware and power supply, Prototype 2 also consists of a belt with eight vibration motors and has two housing for the hardware. The third Prototype is a kidney belt with four attached vibration motors and bags sewn in for the hardware. The last prototype is a belly pocket with four vibration motors and the hardware is stored in the bag of the belly pocket.

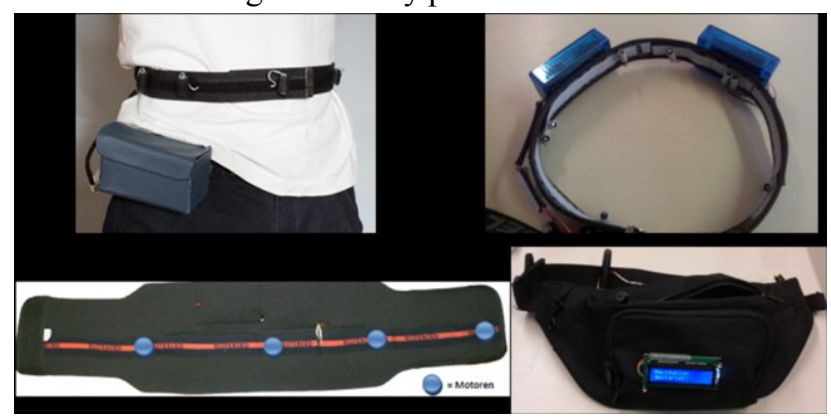

Figure 1: Different vibrating systems for the navigation of blindfolded people. 
Table 1: Enabled vibration motors located on the belts by incoming navigational commands.

\begin{tabular}{|c|c|c|c|c|}
\hline Command & Group 1 (8 motors) & Group 2 (8 motors) & Group 3 (4 motors) & Group 4 (4 motors) \\
\hline Input type & Notebook Keyboard & Notebook Touchpad + GUI & Xbox Game Controller & Touch screen of a Tablet-PC \\
\hline Forward & Front motor at the center. & 2 front motors at the center & Front motor at the center & Front motor at the center \\
\hline Backward & Back motor in the center & 2 back motors at the center & Back motor at the center & Back motor at the center \\
\hline Stop & $\begin{array}{l}\text { Front left/right and back } \\
\text { left/right motors simultaneous }\end{array}$ & $\begin{array}{l}\text { Enabling of the } 2 \text { back motors } \\
\text { at the center for } 0.5 \mathrm{~s}\end{array}$ & $\begin{array}{l}\text { Enabling of the back motor at } \\
\text { the center for a short time }\end{array}$ & $\begin{array}{l}\text { All motors simultaneous for } \\
0.5 \mathrm{~s}\end{array}$ \\
\hline Left & $\begin{array}{l}\text { - Left motor }=\text { step to the left } \\
\text { - front }+ \text { front left motor } \\
\text { consecutively }=45^{\circ} \text { rotation } \\
+ \text { left motor }=90^{\circ} \text { rotation }\end{array}$ & $\begin{array}{l}2 \text { left motors, } 1 \text { vibrotactile } \\
\text { signal }=45^{\circ} \text { rotation to the } \\
\text { left, } 2 \text { signals }=90^{\circ} \text { rotation }\end{array}$ & $\begin{array}{l}\text { Left }+ \text { front motor }=45^{\circ} \\
\text { rotation to the left, } \\
\text { left motor }=90^{\circ} \text { rotation }\end{array}$ & $\begin{array}{l}\text { Left }+ \text { front motor }=45^{\circ} \\
\text { rotation to the left, } \\
\text { left motor }=90^{\circ} \text { rotation }\end{array}$ \\
\hline Right & $\begin{array}{l}\text { Alike the left instructions, but } \\
\text { enabling the motors located } \\
\text { on the right side. }\end{array}$ & $\begin{array}{l}2 \text { right motors, } 1 \text { vibrotactile } \\
\text { signal }=45^{\circ} \text { rotation to the } \\
\text { right, } 2 \text { signals }=90^{\circ} \text { rotation }\end{array}$ & $\begin{array}{l}\text { Right }+ \text { front motor }=45^{\circ} \\
\text { rotation to the right, } \\
\text { right motor }=90^{\circ} \text { rotation }\end{array}$ & $\begin{array}{l}\text { Right }+ \text { front motor }=45^{\circ} \\
\text { rotation to the right, } \\
\text { right motor }=90^{\circ} \text { rotation }\end{array}$ \\
\hline $\begin{array}{l}\text { Attention } \\
\text { step }\end{array}$ & $\begin{array}{l}\text { Step up: front left }+ \text { front } \\
\text { right and back right }+ \text { back } \\
\text { left motors consecutively } \\
\text { Step down: Vice versa to the } \\
\text { step up signal. }\end{array}$ & All motors simultaneous & All motors simultaneous & $\begin{array}{l}\text { Multiple simultaneous ena- } \\
\text { bling of all motors }\end{array}$ \\
\hline
\end{tabular}

To guide the blindfolded person, the groups had to find appropriate locations to place the vibration motors and had also to consider a good coding of the vibrotactile signals. Table 1 reveals the different coding of the systems for navigational commands. All groups placed the vibration motors on a belt around the waist. Group 1-3 used the LabVIEW toolkit for Arduino to communicate between PC and the Arduino BT. Group 4 used Java instead.

\section{Results}

To compare the prototypes with different navigational encodings, two runs in a trail with obstacles had to be absolved. The total time needed to finish the runs was summed up. A contact with an obstacle or barrier tape was counted as a penalty of additional 5 seconds. Table 2 shows the measured time for the runs and the number of committed penalties.

Table 2: Measured time for finishing the trial and number of contacts (penalties) with obstacles.

\begin{tabular}{lllll}
\hline Group & $\begin{array}{l}\text { Time Run 1 } \\
\text { [min] }\end{array}$ & $\begin{array}{l}\text { Time Run 2 } \\
\text { [min] }\end{array}$ & $\begin{array}{l}\text { Penalties } \\
\mathbf{( + 5} \text { s) }\end{array}$ & $\begin{array}{l}\text { Total Time } \\
\text { [min] }\end{array}$ \\
\hline $\mathbf{1}$ & $1: 56$ & $2: 18$ & 2 & $4: 24$ \\
$\mathbf{2}$ & $1: 51$ & $3: 14$ & 4 & $5: 25$ \\
$\mathbf{3}$ & $1: 44$ & $2: 05$ & 5 & $4: 14$ \\
$\mathbf{4}$ & $1: 38$ & $2: 16$ & 4 & $4: 14$ \\
\hline
\end{tabular}

The navigational instructions (Table 1) were given via the Notebook Keyboard, Notebook Touchpad and a GUI, an Xbox Game Controller or the touch screen of a Tablet-PC.

\section{Discussion}

We presented an approach for navigational instructions using vibrotactile stimuli of the skin with four different vibrating systems and different encodings. The results of the vibrating systems performance in the trail with obstacles are shown in Table 2. Within the trail we saw that the systems are easy to use for the guidance of blindfolded people. The number of collisions with obstacles seems at first to be too high for a safe navigation of blind people, but most of the collisions were just slight contacts with the barrier tape of the trail, which was also counted as a penalty.
The realisation of the navigating commands (Table 1) of group 3 and 4 seemed to be the most efficient and demonstrate that a vibrating system which only uses 4 vibration motors and a simple kept encoding can be sufficient to guide blindfolded people. In addition it seems reasonable to assume that a simple system could be superior for navigational tasks than more complex systems, because higher numbers of vibrotactile signals can lead to misinterpretation of the user. For this reason complex systems would probably need more training before use.

The use of vibrotactile signals to give navigational instruction seems to be a promising method. Current efforts are directed towards the integration of a 3D laser scanner into the consisting systems for obstacles detection and navigational instructions.

\section{Acknowledgement}

We would like to thank the engineering students Daniel Mantay, Julian Keßler, Andreas Rösch, Janik Dorer, Claudius Ambs, Frederick Wursthorn, Felix Jung, Simon Krause and Jonas Scherer from the Furtwangen University for the construction of the prototypes.

This work was supported by the Bundesministerium für Bildung und Forschung (BMBF), Kennziffer 01EZ1129A.

\section{Bibliography}

[1] World Health Organization, "Visual impairment and blindness" - Fact Sheet N²82 (2012).

Available online:

http://www.who.int/mediacentre/factsheets/fs282/en/ Last access: February 2013

[2] K. Möller, J. Möller, K. O. Arras, M. Bach, S. Schumann, and J. Guttmann, "Enhanced perception for visually impaired people evaluated in a real time setting", in World Congress on Medical Physics and Biomedical Engineering, O. Dössel and W. C. Schlegel, Eds., (Springer, Munich, Germany, 2009), vol. 25/4, pp. 283-6, 2009.

[3] F. A. Geldard, "Some neglected possibilities of communication," Science, vol. 131, pp. 1583-1588, 1960 . 